\title{
Rosemary Extract Mediated Lifespan Extension in Drosophila Melanogaster
}

\author{
Hua-li Wang, Ze-sheng Zhang, Zhen-ou Sun, Hao \\ Wang* \\ Key laboratory of Food Nutrition and Safety, Ministry of \\ Education \\ Tianjin University of Science \&Technology \\ Tianjin, China \\ China National Center for Food Safety Risk Assessment \\ e-mail: wanghuali@cfsa.net.cn; \\ zhangzesheng@tust.edu.cn; 799746356@qq.com; \\ wanghao@tust.edu.cn
}

\author{
Na-Ma, Hong-Wang \\ School of Biological Engineering,Tianjin University of \\ Science \& Technology \\ Tianjin University of Science \&Technology \\ Tianjin, China \\ e-mail:nana1191086372@163.com; \\ 260554983@qq.com
}

\begin{abstract}
Rosemary (Rosmarinus officinalis L.) has always known a versatile, aromatic herb and addition to being used as a food flavoring is also known medicinally for its powerful antioxidant activity, antibacterial and hepatoprotective properties. In this study we examined the effects of rosemary iextract on the lifespan and aging in Drosophila melanogaster against high-fat induced oxidative injury, and found that it responded to rosemary extract with an increased lifespan and reduced MDA content during aging. We found that lifespan extension by rosemary extract was attributed to its increasing the activity of SOD, CAT and decreasing the content of MDA. Moreover, Realtime-PCR analysis showed that the gene expression of SOD, and CAT was enhanced, in contrast MTH was significantly reduced. In conclusion, these results suggest that the antioxidant and antiaging effect of rosemary extract may, at least in part, be due to its interactions with endogenous antioxidant protective enzymes including SOD and CAT.
\end{abstract}

Keywords-rosemary extract; drosophila melanogaster; antiaging; antioxidation

\section{INTRODUCTION}

Oxidative stress from free radicals in the body has negative effects, and is considered to be one of the causative factors of aging and disease [1]. Antioxidant, a class of substances helped to capture and neutralize free radicals, thereby removing its damage to the bodysubstance, is to prevent the adverse effects of oxygen [2].

In recent years, considerable attention has been devoted to many herbs and spices, which contain many phytochemicals with potential antioxidant capacity [3]. The greatest level of attention among herbs and spices as sources of antioxidants has been focused on rosemary [4]. Rosemary (Rosmarinus officinalis L.) is a perennial herb from Lamiaceae family, typical of the Mediterranean region, which has been believed have many potential biological and pharmacology functions, such as antioxidant, antimicrobial, hepatoprotective and antiproliferative [5-9].
Therefore, in this study, we investigate whether rosemary extract has the capacity to prolong the lifespan of $\mathrm{D}$. melanogaster and its underlying molecular mechanisms.

\section{Materials AND Methods}

\section{A. Chemicals and strains}

Rosemary extract was provided by Tianjin Jianfeng Natural Product Co., Ltd, Tianjin, China, which mainly contained carnosic acid (30.3\%), carnosol (33.2\%), rosmarinic acid (1.5\%), rosmarinic phenol (7.2\%), carnosic acid methyl ester (27.8\%) and other ingredients.

Male fruit flies, wild type, Oregon-R-C (OR) were reared in the vials which $10 \mathrm{~cm} \times 5.0 \mathrm{~cm}$ and covered with plastic film. Those vials were maintained in an incubator with keeping constant temperature $\left(25.0-26.0^{\circ} \mathrm{C}\right)$ and humidity (50-60\%).

\section{B. Culture medium}

The basal diet was prepared according to the standard formulation described previously [10]. In brief, $800 \mathrm{~mL}$ diet contained 72 g corn flour, $72 \mathrm{~g}$ glucose, $10 \mathrm{~g}$ yeast, and $6 \mathrm{~g}$ agar. Ethyl-p-hydroxybenzoate $(0.4 \%)$ was added to the diet to prevent mold growth. High-fat diet was added 10\% lard in basal diet. Experimental diets were prepared by adding rosemary extract $0.2 \mathrm{mg}, 0.5$ or $1.5 \mathrm{mg}$ in the high-fat diet per milliliter, respectively. For the experimental flies, $5 \mathrm{ml}$ of the basal or experimental diets were prepared per vial.

\section{Effect of rosemary extract on longevity}

The 2-day-old OR wild type male flies were divided into five groups ( $\mathrm{n}=200$ each), and housed in 10 vials (20 flies per vial). The first group was reared with the basal diet; the second was fed with high-fat diet, while the other groups were fed with $0.2,0.5$ and $1.5 \mathrm{mg} / \mathrm{mL}$ experimental diet, respectively. The dead flies were counted every 3 days and the remaining alive flies were transferred to another new vial with the same diet. The maximum life spans in this study were calculated as the average life span of the $10 \%$ longest surviving flies. 


\section{Enzyme activity assay}

2-day-old male flies $(n=1000)$ were divided into five groups, with 200 flies in each group. They were fed the diet containing different doses $(0,0.2,0.5,1.5 \mathrm{mg} / \mathrm{mL})$ of rosemary extract for $45 \mathrm{~d}$, the method of culture flies were similarly to survival experiments described above. The male flies were collected under $\mathrm{CO} 2$ anesthesia after starving for 2 $\mathrm{h}$, recorded the average body weight in each group and then stored at $-80{ }^{\circ} \mathrm{C}$. Assay kits were used to measure the SOD, CAT activity and MDA content, meanwhile protein concentration was determined with the BCA protein assay kit.

\section{E. Real-time PCR}

The expressions of mRNA were measured according to our previous method [10]. In brief, total RNA was extracted using the commercial extraction agent TRIzol. PrimeScript RT reagent Kit with gDNA Eraser (TAKARA, Dalian, China) was used to construct cDNA. Then cDNA was synthesized in the MyCycler Thermal Cycler (BIO RAD, USA) and stored at $-20{ }^{\circ} \mathrm{C}$. The target genes were $\mathrm{Cu}-\mathrm{Zn}$ SOD, Mn-SOD, CAT, and MTH. The rp49, a housekeeping gene, was used to normalize the expression of the target genes. Gene expression was calculated on the basis of the comparative threshold cycle (CT) value. Levels of gene expression in all groups were shown as a ratio of the control group value.

\section{F. Statistics}

Data were expressed as means \pm standard deviation. The significance of differences between samples was assessed using T-test and one-way ANOVA. Differences were considered significant when $\mathrm{p}<0.05$.

\section{Results}

\section{A. Effect of rosemary extract on lifespan in Drosophila melanogaster}

The present study showed that the average body weight was significant increased $(\mathrm{P}<0.05)$ in high-fat diet fed flies, meanwhile the mean lifespan and maximum lifespan were shortened compared with that of the control flies (Figure 1). But there was no significant difference in average body weight between the high-fat diet group and rosemarytreatment flies.

The results demonstrated that supplementation of rosemary extract in high fat diet could partially reverse the high fat induced mortality and significantly extended lifespan in a dose-dependent manner (Table I). The result showed that $0.2,0.5$ and $1.5 \mathrm{mg} / \mathrm{mL}$ rosemary treatment extended the mean lifespan of fruit flies $4.33 \mathrm{~d}, 6.06 \mathrm{~d}$ and 7.44 d more, respectively. Rosemary-treated group (1.5 $\mathrm{mg} / \mathrm{mL}$ ) significantly increased the mean lifespan by $17.47 \%$ compared with that of the high-fat group $(\mathrm{P}<0.05)$. In addition, the $0.2,0.5$ and $1.5 \mathrm{mg} / \mathrm{mL}$ Rosemary treatment also significantly extended the maximum lifespan by $4.12 \%$, $8.63 \%$ and $17.47 \%$ compared with that of the high-fat group $(\mathrm{P}<0.05)$.

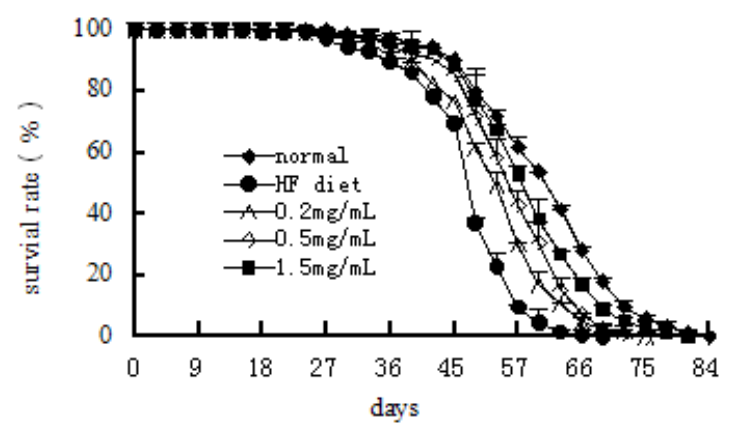

Figure 1. Lifespan curve of Drosophila melanogaster

TABLE I. EFFECT OF ROSEMARY EXTRACT ON LIFESPAN OF Drosophila Melanogaster

\begin{tabular}{|c|c|c|c|c|}
\hline Group & $\begin{array}{c}\text { Rosemary } \\
\text { extract } \\
(\mathrm{mg} / \mathrm{mL})\end{array}$ & $\begin{array}{c}\text { Body weight } \\
(\mu g)\end{array}$ & $\begin{array}{c}\text { Mean lifespan } \\
\text { (d) }\end{array}$ & $\begin{array}{c}\text { Maximum } \\
\text { lifespan } \\
\text { (d) }\end{array}$ \\
\hline \multirow{5}{*}{$\begin{array}{l}\text { Normal } \\
\text { HF diet }\end{array}$} & 0 & $873.76 \pm 37.18$ & $51.26 \pm 3.38$ & $73.58 \pm 2.97$ \\
\hline & 0 & $950.78 \pm 31.30 \#$ & $42.59 \pm 1.63 \#$ & $63.13 \pm 1.34 \#$ \\
\hline & 0.2 & $941.15 \pm 36.80$ & $46.92 \pm 2.82$ & $65.73 \pm 3.12 *$ \\
\hline & 0.5 & $921.08 \pm 44.58$ & $48.65 \pm 1.17^{*}$ & $68.58 \pm 1.04^{* *}$ \\
\hline & 1.5 & $927.51 \pm 34.51$ & $50.03 \pm 2.94 *$ & $72.49 \pm 2.18 * *$ \\
\hline
\end{tabular}

\section{B. Effects of Rosemary extract on the antioxidant enzymes} activities and lipid peroxides concentration in Drosophila melanogaster

Supplementation of rosemary extract could significantly increased the SOD and CAT enzyme activity comparing with the high-fat fed group, while MDA content decreased significantly in a dose-dependent manner. As shown in Table II, supplied rosemary extract of $1.5 \mathrm{mg} / \mathrm{mL}$ could significantly increased the Cu-Zn-SOD enzymes activities, and $0.5,1.5 \mathrm{mg} / \mathrm{mL}$ rosemary-treatment could significantly increase the Mn-SOD enzymes activities $(\mathrm{P}<0.05)$. The activity of CAT was $8.58 \mathrm{U} / \mathrm{mg}$ protein in the high-fat group. In contrast, for the rosemary-treated groups values were 10.05, 11.76 and $11.99 \mathrm{U} / \mathrm{mg}$ protein, respectively. The 0.5 and $1.5 \mathrm{mg} / \mathrm{mL}$ rosemary-treated group significantly increased CAT activity in fruit flies compared with that of the high-fat fed group $(\mathrm{p}<0.05)$.

Supplementation with rosemary extract attenuated high fat diet-induced oxidative damage of lipid and reduced the content of MDA. Supplementation with $1.5 \mathrm{mg} / \mathrm{mL}$ rosemary extract significantly decreased the MDA level from $3.93 \mathrm{nmol} / \mathrm{mg}$ protein to $3.11 \mathrm{nmol} / \mathrm{mg}$ protein $(\mathrm{p}<0.01)$, indicating that rosemary extract can prevent oxidative stress. 
TABLE II. EFFEct OF ROSEMARy EXtract ON CU-Zn-SOD, MNSOD, CAT Activity and MDA Content in Drosophila Melanogaster

\begin{tabular}{|c|c|c|c|c|c|}
\hline Group & $\begin{array}{c}\text { Rosemar } \\
\text { y } \\
\text { Extract } \\
(\mathrm{mg} / \mathrm{mL} \\
)\end{array}$ & $\begin{array}{c}\text { Cu-Zn- } \\
\text { SOD } \\
\text { (U/mg } \\
\text { pro) }\end{array}$ & $\begin{array}{c}\text { Mn-SOD } \\
\text { (U/mg pro) }\end{array}$ & $\begin{array}{l}\text { CAT } \\
\text { (U/mg } \\
\text { pro） }\end{array}$ & $\begin{array}{l}\text { MDA } \\
\text { (nmol/ } \\
\text { mg } \\
\text { pro) }\end{array}$ \\
\hline Normal & 0 & $42.36 \pm 2.65$ & $45.74 \pm 4.14$ & $12.35 \pm 1.35$ & $2.48 \pm 0.22$ \\
\hline \multirow[t]{4}{*}{ HF diet } & 0 & $37.41 \pm 2.52 \#$ & $38.14 \pm 3.81 \#$ & $8.58 \pm 1.71 \# \#$ & $3.93 \pm 0.24 \# \#$ \\
\hline & 0.2 & $39.84 \pm 2.93$ & $39.69 \pm 4.17$ & $10.05 \pm 1.37$ & $3.55 \pm 0.26 *$ \\
\hline & 0.5 & $40.04 \pm 3.40$ & $43.53 \pm 3.00 *$ & $11.76 \pm 1.21^{*}$ & $3.31 \pm 0.25^{* *}$ \\
\hline & 1.5 & $41.78 \pm 3.46^{*}$ & $\begin{array}{c}45.96 \pm 3.07 * \\
*\end{array}$ & $11.99 \pm 1.34^{*}$ & $3.11 \pm 0.38^{* *}$ \\
\hline
\end{tabular}

\section{C. mRNA expression levels of antioxidant genes}

As to the gene expression, mRNA expression of $\mathrm{Cu}-\mathrm{Zn}$ SOD, Mn-SOD, CAT, and MTH in wild type flies was studied. Rp49 was selected as an internal control gene. The expression level of $\mathrm{Cu}-\mathrm{Zn}-\mathrm{SOD}$ and Mn-SOD was increased in rosemary-treated group compared with that in the high-fat group, meanwhile there was a significant increase in 1.5 $\mathrm{mg} / \mathrm{mL}$ group $(\mathrm{p}<0.05)$. Similarly, gene expression of CAT was increased in $0.5 \mathrm{mg} / \mathrm{mL}$ and $1.5 \mathrm{mg} / \mathrm{mL}$ group compared with that in the high-fat group $(\mathrm{p}<0.05)$. In contrast, gene expression of MTH was only significantly decreased in $1.5 \mathrm{mg} / \mathrm{mL}$ rosemary-treated group compared with that in the high-fat group (Figure 2).

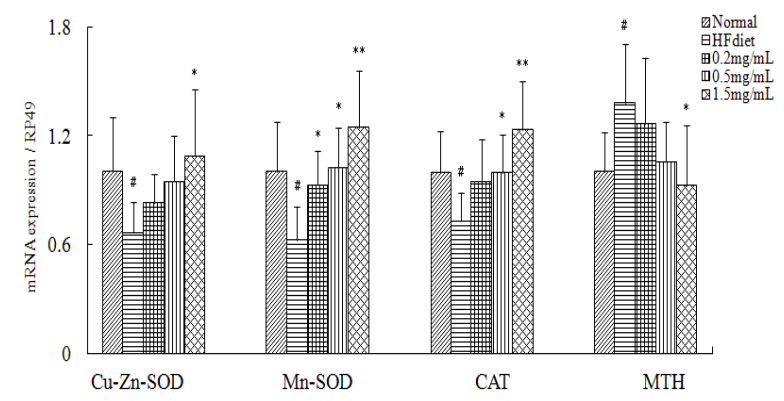

Figure 2. Effect of Rosemary extract on Cu-Zn-SOD, Mn-SOD, CAT, and MTH mRNA expression in Drosophila melanogaster

$\# \mathrm{P}<0.05, \# \# \mathrm{P}<0.01$ vs Normal group; ${ }^{*} \mathrm{P}<0.05,{ }^{* *} \mathrm{P}<0.01$ vs HF diet group

\section{Discussion}

High-fat diet can induce higher levels of reactive oxygen species (ROS), evidenced by hydrogen peroxide emission from mitochondria [11], and shift the cellular redox environment to a more oxidized state, and decreases the redox-buffering capacity in the absence of any change in mitochondrial respiratory function [12]. The oxidative stress hypothesis is one of the leading mechanistic explanations for aging [13]. Recent studies reveal that ROS cause oxidative damage to macromolecules that leads to loss of molecular function and ultimately cellular, organ and organismal senescence.
The present study showed that the mean lifespan and maximum lifespan of high-fat diet fed fruit flies were significant shorten $(\mathrm{P}<0.05)$, accompanied with the activity and mRNA level of antioxidant protective enzymes were significant decreased compared with that in the normal group $(\mathrm{P}<0.05)$ (Table II).

To help to scavenge free radicals by terminating the propagation of ROS reaction, antioxidant defenses including endogenous antioxidant enzymes such as superoxide dismutase (SOD), catalase (CAT) and exogenous dietary antioxidant such as vitamin $\mathrm{C}$ and $\mathrm{E}$ is an essential anchor [14]. Rosemary extracts possesses a greater antioxidant capacity than most other fruits and vegetables. Our study found that adding rosemary extract could significantly increase $\mathrm{Cu}-\mathrm{ZnSOD}, \mathrm{Mn}-\mathrm{SOD}$ and CAT enzyme activity in male flies. It was agreement with Bakirel who found that ethanolic extract of the leaves of Rosmary could significantly inhibit the lipid peroxidation and activate the antioxidant enzymes such as SOD, CAT in alloxan-diabetic rabbits [15].

It is believed that accumulation of oxidative damages caused by reactive oxygen species (ROS) is one of the major contributors responsible for aging including fruit flies. MDA is a major oxidative degradation product of membrane unsaturated fatty acid. Posadas found after fedding with a standard kibble (80\%) supplemented with turkey breast (20\%) containing one of two different rosemary concentrations $(0.2 \%$ and $0.02 \%)$ for 12 weeks, the MDA coutent in heart and brain (cortex and hippocampus) of aged Wistar rats were decreased [16]. We found treatment of rosemary extract significantly could attenuate high fat dietinduced oxidative damage of lipid and restore lifespan of fruit flies.

Real-time PCR results displayed that rosemary extract upregulated the antioxidant protective genes mRNA expression level of SOD and CAT, and the increasing trend were consistent with the corresponding anti-oxidation enzyme activities. The Methuselah (MTH) gene in D. Melanogaster has been a major target of interest in the biology of aging, which is the 3rd chromosome in vivo of Drosophila genes encoding g protein-coupled receptors, and has been shown to be involved in longevity in fruit flies [17]. Flies with reduced expression of the $G$ protein-coupled receptor gene methuselah ( $\mathrm{MTH}$ ) appear to have enhanced resistance to oxidative stress [18]. Similarly, Baldal proved that MTH endogenous ligand gene knockout or overexpression of peptide antagonists of $\mathrm{MTH}$ receptor extends life span of fruit flies [19]. In this study, we found that flies supplementation with rosemary extract reduced mRNA level of MTH (Figure 2). It was in agreement with Cheng who reported that black tea extract could prolong lifespan of fruit flies by enhancing Cu-Zn-SOD, CAT and reducing MTH mRNA expression [20].

In conclusion, the results presented indicate that rosemary extract could significantly extend the lifespan, attenuate the oxidation and increase the activities of antioxidant enzymes in fruit flies. The anti-aging activity of rosemary extract was at least partially associated with its 
interaction with antioxidant protective enzymes and genes including SOD, and CAT.

\section{ACKNOWLEDGMENT}

This project was supported by the National Natural Science Foundation of China (Grant No. 31201322) ; the National Science \& Technology Pillar Program during the 12th Five-year Plan Period (Grant No. 2012BAD33B05) ; Tianjin City High School Science \& Technology Fund Planning Project (Grant No. 20100609).

\section{REFERENCES}

[1] C. Peng, Y.Y. Zuo, K.M. Kwan, Y.T. Liang, K.Y. Ma, H.Y.E. Chan, Y. Huang, H.J. Yu, and Z.Y. Chen, "Blueberry extract prolongs lifespan of Drosophila melanogaster," Experimental Gerontology, vol. 47, 2011, pp. 170-178.

[2] L.M. Wills, B. Shukitt-Hale, J.A._Joseph, "Modulation of cognition and behavior in aged animals: role for antioxidant- and essential fatty acid-rich plant foods," American Journal of Clinical Nutrition, vol. 89(5) , 2009, pp. 1602S-1606S.

[3] M.A. Lila, "From beans to berries and beyond: teamwork between plant chemicals for protection of optimal human health," Annals of the New York Academy of Sciences, vol. 1114, 2007, pp. 372-380.

[4] N. Erkan, G. Ayranci, and E. Ayranci, "Antioxidant activities of rosemary (Rosmarinus Officinalis L.) extract, blackseed (Nigella sativa L.) essential oil, carnosic acid, rosmarinic acid and sesamol," Food Chemistry, vol. 110(1) , 2008, pp. 76-82.

[5] O.I. Aruoma, J.P. Spencer, R. Rossi, et al. "An evaluation of the antioxidant and antiviral action of extracts of rosemary and provençal herbs," Food \& Chemical Toxicology An International Journal Published for the British Industrial Biological Research Association, vol. 34(5) , 1996, pp. 449-456.

[6] B. Biljana, M.D. Neda, and S. Isidora, "Antimicrobial and antioxidant properties of rosemary and sage (Rosmarinus officinalis L. and Salvia officinalis L., Lamiaceae) essential oils,” Journal of Agricultural \& Food Chemistry, vol. 55(19), 2007, pp. 7879-7885.

[7] A.L. Martínez, M.E. González-Trujano, and F. Pellicer, "Antinociceptive Effect and GC/MS Analysis of Rosmarinus officinalis L. Essential Oil from its Aerial Parts," Planta Medica, vol. 75(5) , 2009, pp. 508-511.
[8] A. Amin, and A.A. Hamza, "Hepatoprotective effects of Hibiscus, Rosmarinus and Salvia on azathioprine-induced toxicity in rats," Life Sciences, vol. 77(3) , 2005, pp. 266-278.

[9] S. Cheung, J. Tai, “Anti-proliferative and antioxidant properties of rosemary Rosmarinus officinalis,” Oncology Reports, vol. 17(6) , 2007, pp. 1525-1531.

[10] Z. Zhang, S. Han, and H. Wang, "Lutein extends the lifespan of Drosophila melanogaster," Archives of Gerontology and Geriatrics, vol. 58(1) , 2014, pp. 153-159.

[11] Y. Li, and V. Periwal, "Synergy in Free Radical Generation is Blunted by High-Fat Diet Induced Alterations in Skeletal Muscle Mitochondrial Metabolism,” Biophysical Journal, vol. 104(5) , 2013, pp. 1127-1141.

[12] E.J. Anderson, M.E. Lustig, and K.E. Boyle, "Mitochondrial H2O2 emission and cellular redox state link excess fat intake to insulin resistance in both rodents and humans," Journal of Clinical Investigation, vol. 119(3) , 2009, pp. 573-581.

[13] D. Harman, "Aging: a theory based on free radical and radiation chemistry,” Journal of Gerontology, vol. 11(3) , 1956, pp. 298-300.

[14] J.H. Hong, and I.S. Lee, "Effects of Artemisia capillaris ethyl acetate fraction on oxidative stress and antioxidant enzyme in high-fat diet induced obese mice," Chemico-Biological Interactions, vol. 179(23) , 2009, pp. 88-93.

[15] B. Tülay, B. Utku and K. Oya Ustüner, "In vivo assessment of antidiabetic and antioxidant activities of rosemary (Rosmarinus officinalis) in alloxan-diabetic rabbits,” Journal of Ethnopharmacology, vol. 116(1) , 2008, pp. 64-73.

[16] S.J. Posadas, V. Caz, and C. Largo, "Protective effect of supercritical fluid rosemary extract, Rosmarinus officinalis, on antioxidants of major organs of aged rats," Experimental Gerontology, vol. 44, 2009, pp. 383-389.

[17] Y.J. Lin, L. Seroude, and S. Benzer, "Extended life span and stress resistance in the Drosophila mutant Methuselah. Science 282:943-6," Science, vol. 282(5390) , 1998, pp. 943-946.

[18] M.S. Grotewiel, I. Martin, P. Bhandari, E. Cook-Wiens, "Functional senescence in Drosophila melanogaster," Ageing Research Reviews, vol. 4, 2005, pp. 372-397

[19] E.A._Baldal, W._Baktawar, P.M. Brakefield, B.J. Zwwan, "Methuselah life history in a variety of conditions, implications for the use of mutants in longevity research,” Experimental gerontology, vol. 41(11), 2006, pp. 1126-1135.

[20] P. Cheng, H.Y.E._Chan, L. _Yuk Man, H. _Yu, C.Z_. Yu, "Black tea theaflavins extend the lifespan of fruit flies," Experimental Gerontology, vol. 44(12) , 2009, pp. 773-783. 